International Neuropsychiatric Disease Journal

5(3): 1-10, 2016; Article no.INDJ.20422

ISSN: 2321-7235, NLM ID: 101632319

SCIENCEDOMAIN international

www.sciencedomain.org

\title{
Influence of Psychotropic Drugs upon Neuropsychological Test Performance
}

\author{
Edward Helmes $^{1^{\star}}$ \\ ${ }^{1}$ Department of Psychology, James Cook University, Australia.
}

Author's contribution

The sole author designed, analyzed and interpreted and prepared the manuscript.

Article Information

DOI: 10.9734/INDJ/2016/20422

Editor(s):

(1) Catherine Fassbender, Department of Psychiatry and Behavioral Sciences, University of California Davis,

UC Davis M.I.N.D. Institute, USA

Reviewers:

(1) Diana C. Tapia-Pancardo, National Autonomous University of México, Mexico.

(2) Patrizio Tressoldi, Università di Padova, Italy.

(3) Mufutau A Yunusa, Usmanu Danfodiyo University, Sokoto, Nigeria.

Complete Peer review History: http://sciencedomain.org/review-history/11586

Review Article

Received $27^{\text {th }}$ July 2015

Accepted $5^{\text {th }}$ September 2015

Published $28^{\text {th }}$ September 2015

\begin{abstract}
Commonly used psychotropic medications are widely presumed to have deleterious effects on neuropsychological test performance. However, given the special difficulties of neuropsychological assessment with psychiatric populations, these effects have rarely been directly examined for differential, quantitative effects on test scores. A comprehensive neuropsychological test battery is described that assesses executive functions, memory, language comprehension, motor and sensory functions, and manual praxis. Data are presented on 233 psychiatric patients (70 females, 163 males) referred for neuropsychological assessment. All people with known or suspected brain damage were excluded, with 100 not taking any type of psychoactive medication. Comparisons between an unmedicated group and those taking the most common medications showed differences on tests of perseverative responses and praxis. No effects for nonverbal memory, simple motor functions, basic intellectual processes or visuomotor functions were noted. Implications for the assessment of people taking psychotropic medications are discussed.
\end{abstract}

Keywords: Psychotropic drugs; neuropsychological tests; psychiatric patients; executive functions; praxis. 


\section{INTRODUCTION}

Neuropsychological assessment in psychiatric populations has long provided additional complications beyond those present in other applications [1]. Complex medical histories, often including alcohol and drug use as well as physical health problems, suggest a range of factors that may influence cognitive functioning, in addition to the fundamental changes in cognitive process associated with the particular underlying psychiatric disorder. Multiple possible aetiologies and high levels of co-morbidity are among the known reasons for the high degree of variability in symptoms of disorders [2]. The increasing prevalence of prescriptions of psychoactive medications for the treatment of increasingly common psychological disorders [3] raises concern about the influence of such medications upon cognitive and neuropsychological assessment instruments. The common use of psychoactive medication, questionable and varying motivation on the part of the clients, and the heterogeneity of cognitive problems encountered have challenged practitioners in this area [4]. The use of psychotropic medication and other nonprescription drugs [5] by psychiatric patients has led to particular concern over the interpretation of neuropsychological tests [1]. Such medication is very likely to affect test performance in specific ways, ones which regrettably remain largely undocumented [6].

There is some systematic research in this area, mostly related to the associations of the use of alcohol and other non-prescription drugs $[7,8,9]$ and of the influence of medication on cognitive functioning in people with schizophrenia (see [10] for a recent review). The literature is contradictory, with some studies claiming little or no effect, and others showing substantial effects. For example, Yozawitz [11] claimed no differences between medicated and unmedicated patients on his battery of tests, and Irani et al. [10] also did not find consistent effects of medication. In contrast, Bornstein, Nasrallah, Olson, Coffman, Schwartzkopf, and Torello [12] reported general impairments and Prelick, Stastny, Katz, Meyer and Mattis [13] reported slowed information processing and poor recent memory.

Studies have largely been concerned with schizophrenia (e.g., [14] and major depression (e.g., [15]), not the more diverse group of psychiatric patients in general. While people with schizophrenia have often been regarded as the group most likely to show evidence of brain dysfunction upon neuropsychological tests $[16,17$, $18,19,20$ ] or on brain imaging [21], many individual exceptions occur. There are neuroanatomical abnormalities in the brains of many people with schizophrenia that correlate with behavioral abnormalities, but these changes are not specific to schizophrenia [22]. In contrast, several studies have reported improved performance on measures of distractibility and attention [23,24] in people with schizophrenia taking neuroleptic medication at the time of testing in comparison to those not taking such medication. More commonly, impairments in information processing measures and recent memory have been reported $[13,25,26]$, as well as both more general impairments [12,27] and very specific deficits [28]. Howard, Hogan and Wright [29] noted minimal effects on the Halstead-Reitan battery, but suggested that individual drugs might have effects for particular age and diagnostic groups. Gruzelier and Hammond [30] also stressed the variability of effects of chlorpromazine upon different measures of cognitive performance. As an illustration of the complexity of the area, they point out that chlorpromazine alone has over 150 metabolites.

Most research in the area has used a variant of the Halstead-Reitan approach, which carries with it the statistical complications associated with the use of cutting scores [31]. Here, the influence of medication is explored using a variant of the Montreal Neurological Institute neuropsychological test battery that does not rely on the use of fixed cutting scores. Kolb and Wishaw [32] briefly outline some of the tests used in this approach in their section on "Informal Composite Batteries". Their later edition [33] describes a very similar collection of tests as the Western Ontario battery. Tests from this approach were selected to provide the benefits of simple instructions and sensitivity to major cognitive abilities and functional regions of cerebral cortex. The aim of the present study is to determine whether performance on tests and, by inference, related cognitive domains differs between groups of psychiatric patients taking different types of psychoactive medication from those not doing so.

\section{METHODS}

\subsection{Subjects}

Cases were taken from the neuropsychological test files of the assessment service of an urban tertiary psychiatric hospital. Tests were administered during April 1979 to October 1986. Over 500 files were reviewed and 345 with 
relatively complete test battery results and valid administration retained. A valid administration was one in which the examiner judged the client's attention to the tests and motivation to be acceptable from the client's behaviour and selfreport. Commonly those with limited enthusiasm for the testing were not prepared to complete all the tests. All were provided with an explanation of the purpose of the assessment and had any questions answered. The intake process of the hospital included mention of assessment procedures and reassurances that no information that included identifying information would be released. Those 112 cases with independent evidence of brain damage or dysfunction were eliminated. Such evidence consisted of positive findings on computed tomography (CT), magnetic resonance or radionuclide scan, an abnormal EEG, or reports of brain injury or damage from surgical or medical history.

This left a total of 233 cases (70 females and 163 males). The average age was 32.7 years $(S D=$ 15.75 , range 13-70), with a mean of 10.3 years of education ( $S D=3.07$, range $2-19$ ). A total of 100 cases were not taking active psychotropic medication at the time of testing, while 133 were doing so. Of the group taking medication, 96 were taking neuroleptics (of whom 43 were taking antiParkinson drugs), 28 taking antidepressants, 7 taking lithium, 3 taking anti-epileptics and 2 were taking sedatives. Both tricyclic and newer antidepressants were in use during the period of data collection, but separating the sample taking antidepressants into subsamples would have left sample sizes too small for analysis. Use of alcohol and non-prescription drugs was actively discouraged while in hospital. Only data from those taking the three most commonly used medications are reported here. Diagnoses were given according to the international system [34] at both admission and discharge. Where possible, the discharge diagnosis is reported. The most frequent diagnosis was personality disorder (code $301, n=93$ ), followed by schizophrenia (code 295, $\mathrm{n}=65$ ), affective disorder (code 296, $\mathrm{n}=18$ ), neuroses (code 300, $n=31$ ), major psychoses (codes 291, 292, 298, $\mathrm{n}=87$ ), and all other codes $(n=105)$.

The two classes of individuals taking neuroleptic medication contained the bulk of cases with schizophrenia $(43 \%$ of neuroleptic only and $71 \%$ of neuroleptic plus anti-Parkinson drug were diagnosed as having schizophrenia). Most cases with schizophrenia (85\%) were taking neuroleptic drugs. However, the group taking antidepressants contained only $33 \%$ of the diagnosed affective disorder cases, while $38 \%$ of them were receiving neuroleptics. Fifty-seven (88\%) of the cases with schizophrenia were taking some type of medication $\left(x^{2}=34.5,1 d f, p<.001\right)$. The corresponding figure for those with a psychosis was $74\left(85 \% ; x^{2}=44.4,1 d f, p<.001\right)$.

\subsection{Measures}

Tests of specific functions were selected to be measures of basic cognitive functions, each primarily associated with a single neurocognitive system, in as much as such a goal is possible. This approach is in contrast to measures such as the Category Test [35] or Seguin Form Board [36] that require intact functioning of several functions for good performance and can be negatively affected by both focal damage to any of several systems or by widespread damage. The tests that were selected for use from those in the Western Ontario collection comprised a series that were intended to be sensitive to subtle forms of cerebral dysfunction, and also to cover the major areas of psychological functioning in areas known to be related to specific regions of cerebral cortex. The domains that were measured included overall intelligence, verbal and nonverbal memory, language, sensorimotor, visuospatial, praxis, and executive functions. The specific tests that were used are outlined below.

\subsection{Intelligence}

Data collection spanned the introduction of revised forms of the Wechsler tests. Because of the increased error associated with estimating scores from one version on another (e.g., [37]), scores on these measures will not be presented. Current applications would be based on the use of the latest edition of the Wechsler Adult Intelligence Scale [38].

\subsection{Memory}

Memory functions were generally assessed with one of the versions of the Wechsler Memory Scale (WMS). Similar considerations regarding changes to the content of the measures and changes in norms means that the scores on the Wechsler memory measures are not considered here. The latest version of the WMS [39] would be appropriate now. Kimura's [40] Recurring Figures test was regularly used to provide a test of visuospatial recognition memory. Twenty 
stimulus cards are followed by 100 probe cards, providing for a maximum number correct of 40 , with a maximum number correct of 16 for the 40 cards used for the delayed recognition trial. The scores used here are the number correct for the immediate recall and the score for the delayed recall.

\subsection{Language}

In addition to informal observations of language functions, receptive language was assessed using the Short Token Test [41], which also provides a measure of color naming. Only the number correct score for the main administration was used; all participants correctly named all the colors.

\subsection{Sensorimotor Function}

In cases in which observations or self-report suggested that the person was not right-hand dominant, a handedness questionnaire [42] was used with scores of $7 / 8$ or $8 / 8$ taken to reflect predominant hand use. Scores lower than $7 / 8$ were labeled as ambidextrous or poorly lateralized [43]. Grip strength was evaluated in kilograms using a dynamometer [44] over three trials for both left and right hands (and also reported for dominant and non-dominant hands). Motor speed was assessed using a mechanical finger tapping apparatus [45] taking the average number of taps for each hand over two, 10second trials. Touch sensory thresholds were processed using the two-point touch procedure [46] with two trials averaged for each hand. Thresholds were measured in millimeters.

\subsection{Visuospatial Function}

Visuospatial functions were assessed using the Geneva lines [47] and the drawing of a bicycle [48]. The 21-point scoring system used for the bicycle drawing is similar to that described by Lezak et al. [1] Measures for the Geneva Lines were times (in seconds) recorded by stopwatch for left-to-right and right-to-left trials and number of correct trials out of 8 in each direction, which followed 4 practice trials in each direction.

\subsection{Praxis}

The Copying Movements Test [49] was used, as well as the same drawing test, that of a bicycle [1]. The scoring method outlined by Kimura and Archibald [49] was used, with a maximum correct score of 24 for each hand.

\subsection{Executive Functions}

The Nelson [50] variation of the Wisconsin Card Sorting Test [51] was used on the grounds that the greater degree of cueing and reduction in ambiguous stimuli would make its administration more acceptable to the target population. Only cards with unambiguous links to the key cards were used (24 per set, giving a total of 48 cards, with runs of 6 correct to make a category). Scores used were the number of categories completed out of 6 and the number of perseverative responses as defined by Nelson. Table 1 outlines the tests used in the present battery. Administration and scoring instructions for these tests are provided by Kimura [52], with Lezak, et al. [1] also providing some of them.

Table 1. Tests and measures used in neuropsychological battery

\begin{tabular}{lll}
\hline Test (measure) & Function & Source \\
\hline Recurring figures & Memory & Kimura [40] \\
Short token test & Language comprehension & DeRenzi and Faglioni [41] \\
Handedness questionnaire & Handedness & Kimura [42] \\
Grip strength & Motor strength; Lateralization & Dodrill [44] \\
Finger tapping & Motor speed; Lateralization & Halstead [35] \\
Two-point thresholds & Sensory functions & Corkin et al. [46] \\
Geneva lines & Visuomotor speed; Visual neglect & Rey [63]; Kimura et al. [47] \\
Bicycle drawing & Praxis & Lezak [48] \\
Modified card sorting test & Mental set; Executive functions & Nelson [50] \\
Copying movements & Praxis; Motor sequencing & Kimura and Archibald [49] \\
& & Kimura [45] \\
\hline
\end{tabular}




\subsection{Procedure}

Referrals for neuropsychological assessment were made by staff psychiatrists, registrars or psychologists of an urban tertiary psychiatric facility. The great majority of cases were inpatients at the time of assessment, but some were seen as outpatients following discharge. All had a thorough medical history completed by a staff psychiatric specialist and a comprehensive psychosocial history completed by a social worker that generally involved an interview with both the patient and a family member or significant other.

An experienced examiner administered and scored all tests. Other tests were administered to supplement the present battery when warranted by the case. Those results are not presented here.

Comparisons between the performance of the group not taking medication were made with the predicted mean scores of the norms reported by Mitrushina, Boone, Razani, and D'Elia [53], where possible (grip strength, and finger tapping for dominant and non-dominant hands), and Nelson Modified Card Sorting scores. Comparisons with published norms used the 30-34 age group as being closest in age to the present sample. Comparisons of the group not taking medication and the groups taking neuroleptic drugs, neuroleptic drugs plus anti-Parkinson drugs, and antidepressants were made using age and education as covariates. Significant effects for drug group comparisons were supplemented with Tukey hsd tests. All statistical calculations were performed using SYSTAT [54].

\section{RESULTS}

There was no difference in the proportion of men and women taking medication (44\% males and $34 \%$ females; $\left.x^{2}=0.35,1 d f, p=.555\right)$. There were also no differences in the proportion taking medication among those having the diagnoses of neuroses $\left(x_{2}^{2}=0.26,1 d f, p=.611\right)$, personality disorders $\left(x^{2}=3.7,1 d f, p=.055\right)$, and other diagnoses $\left(x^{2}=1.3,1 d f, p=.262\right)$ between medication and no medication groups. There were higher proportions of cases taking medication in the schizophrenia $\left(x^{2}=34.5,1 d f, p<.001\right)$, psychosis $\left(x^{2}=44.4,1 d f, p<.001\right)$, and affective disorder diagnostic groups $\left(x^{2}=5.5,1 d f\right.$, $p=.019)$.

Medication usage was not confirmed for 18 people. The final sample thus comprised 65 females and 150 males, with a mean age of 31.4 years $(S D=14.93)$ and mean years of education of $10.4(S D=3.10)$.

For the number of categories for the Nelson variation of card sorting, the mean difference was 0.2 between these data and the norm reported (p. 1011) by Mitrushina et al. [53] $(95 \% \mathrm{Cl}-0.08$ to -0.32). Mitrushina et al. [53] report the number of perseverative errors whereas the current data report percentages instead so this comparison was not possible. Grip strength was lower in the unmedicated patients for both dominant and nondominant hands for both genders. For males, the difference between the present data and the mean of the norm group predicted scores was $-13.4 \mathrm{~kg}$. $(95 \% \mathrm{Cl}-14.1$ to -12.7$)$ for the dominant hand and $-12.3 \mathrm{~kg}$. for the non-dominant hand $(95 \% \mathrm{Cl}-13.0$ to -11.6). For females, the difference between predicted norms and the present data was -11.3 $\mathrm{kg}$. $(95 \% \mathrm{Cl}-12.3$ to -10.2$)$ for the dominant hand and $-11.0 \mathrm{~kg}$. (95\% Cl -11.9 to -10.0$)$ for the nondominant hand. Comparisons were also possible for tapping speed. For males for the dominant hand, the difference with the 30-34 age group was $-7.8(95 \% \mathrm{Cl}-8.5$ to -7.2$)$ and -7.4 for the nondominant hand $(95 \% \mathrm{Cl}-8.0$ to -6.8$)$. For females, the difference in tapping speed was $-1.8(95 \% \mathrm{Cl}$ 2.8 to -0.80 ) for the dominant hand and a 1.2 difference for the non-dominant hand in favour of the current data (95\% $\mathrm{Cl} 0.2$ to 2.2$)$.

For the comparison of the group not receiving medication with the three medication groups, the covariates of age and years of education were not universally significant. Age was a significant covariate for the delayed recurring figures score, left and right hand grip strength, dominant and non-dominant grip strength, right and left Geneva lines, number of categories and number of perseverative responses on modified card sorting, right hand and dominant and non-dominant hand 2-point touch thresholds, and right and left hand and dominant and non-dominant hand tapping speed scores. Years of education was a significant covariate for the delayed recurring figures score, all four copying movements scores, left and right Geneva lines scores, right and dominant and nondominant 2-point thresholds, left and right and dominant and non-dominant hand tapping speeds.

A MANOVA comparing 15 test scores for unmedicated and three drug groups was not significant (Pillai's trace $=.11, F(15,115 d f)=.93$, $p=.53$ ) and had a notably reduced sample size, resulting in a lower statistical power. Univariate analyses of covariance were conducted as a compromise between the number of statistical 
tests conducted and the sample size available. Table 2 reports the means for medication groups on the measures of the battery outlined in Table 1 with raw and scores adjusted for age and education for the group not receiving medication. Significant effects for the drug group comparison were found for the right hand copying movements score $(F=2.95,3,186 d f, p=.034)$. The Tukey hsd test indicated the group taking neuroleptics plus anti-Parkinson drugs were lower than in the group taking no medication $(p=.049,95 \% \mathrm{Cl} 0.02$ to 3.87). The same pattern was evident for copying movements with the dominant hand $(F=2.92,3$, $171 d f, p=.036)$, with the same pattern on the Tukey hsd test $(p=.063)$. Another effect was observed for number of perseverative responses on the card sorting test $(F=2.84,3,176 d f, p$ $=.040$ ). The Tukey hsd test showed the group taking both anti-Parkinson and neuroleptic drugs had more perseverative responses than the group not taking medication $(p=042,95 \% \mathrm{Cl}-21.94$ to 0.40).

Table 2. Comparison of neuropsychological test scores adjusted for age and education for unmedicated and three medication groups

\begin{tabular}{|c|c|c|c|c|c|c|c|c|c|c|}
\hline \multirow[t]{3}{*}{ Measure } & \multicolumn{6}{|c|}{ No medication } & \multicolumn{4}{|c|}{ Medication } \\
\hline & \multicolumn{2}{|c|}{ Raw } & \multicolumn{2}{|c|}{ Adjusted } & \multicolumn{2}{|c|}{ Neuroleptic } & \multicolumn{2}{|c|}{$\begin{array}{l}\text { Neuroleptic + } \\
\text { Anti-parkinson }\end{array}$} & \multicolumn{2}{|c|}{ Antidepressant } \\
\hline & Mean & SD & Mean & SE & Mean & SE & Mean & SE & Mean & SE \\
\hline $\begin{array}{l}\text { Recurring } \\
\text { figures }\end{array}$ & 21.6 & 10.18 & 21.5 & 1.06 & 16.9 & 1.56 & 18.3 & 1.55 & 18.1 & 2.08 \\
\hline Delay & 7.8 & 5.03 & 7.7 & 0.52 & 5.03 & 0.79 & 6.7 & 0.79 & 6.3 & 1.01 \\
\hline $\begin{array}{l}\text { Short token } \\
\text { test } \\
\text { Card sorting }\end{array}$ & 34.0 & 1.58 & 33.9 & 0.26 & 33.3 & 0.36 & 32.9 & 0.37 & 33.3 & 0.51 \\
\hline No. categories & 5.1 & 1.66 & 5.0 & 0.18 & 4.7 & 0.28 & 4.7 & 0.28 & 5.5 & 0.37 \\
\hline $\begin{array}{l}\text { Perseveration } \\
\text { Grip strength }\end{array}$ & 13.5 & 20.58 & $14.5^{\star}$ & 2.29 & 20.0 & 3.58 & $25.7^{*}$ & 33.9 & 13.0 & 4.85 \\
\hline Right & 33.8 & 11.46 & 33.0 & 1.15 & 31.5 & 1.64 & 33.3 & 1.68 & 33.6 & 2.26 \\
\hline Left & 32.8 & 11.72 & 32.0 & 1.23 & 29.8 & 1.75 & 32.3 & 1.79 & 31.8 & 2.41 \\
\hline Dominant & 34.2 & 11.44 & 33.4 & 1.21 & 31.4 & 1.74 & 32.9 & 1.72 & 4.0 & 2.26 \\
\hline $\begin{array}{l}\text { Non-dominant } \\
\text { Finger } \\
\text { tapping }\end{array}$ & 32.4 & 12.29 & 31.6 & 1.33 & 28.2 & 1.91 & 31.8 & 1.88 & 31.4 & 2.48 \\
\hline Right & 43.1 & 9.80 & 42.3 & 1.08 & 39.6 & 1.53 & 15.3 & 1.55 & 43.7 & 2.04 \\
\hline Left & 39.6 & 8.87 & 39.0 & 1.06 & 37.4 & 1.49 & 39.0 & 1.52 & 28.6 & 2.00 \\
\hline Dominant & 43.4 & 10.19 & 42.5 & 1.18 & 39.9 & 1.67 & 42.5 & 1.66 & 44.0 & 2.12 \\
\hline $\begin{array}{l}\text { Non-dominant } \\
\text { Copying } \\
\text { movements }\end{array}$ & 39.3 & 8.95 & 38.7 & 1.11 & 36.5 & 1.57 & 38.8 & 1.56 & 39.1 & 1.99 \\
\hline Right & 21.2 & 3.32 & $20.8^{*}$ & 0.43 & 19.6 & 0.61 & $18.8^{*}$ & 0.62 & 21.1 & 0.84 \\
\hline Left & 20.1 & 3.00 & 19.8 & 0.43 & 18.9 & 0.60 & 18.5 & 0.62 & 18.9 & 0.83 \\
\hline Dominant & 21.1 & 3.37 & $20.7^{*}$ & 0.46 & 19.3 & 0.66 & $18.7^{*}$ & 0.65 & 20.9 & 0.85 \\
\hline Non-dominant & 20.4 & 3.12 & 20.0 & 0.47 & 18.7 & 0.67 & 18.5 & 0.66 & 19.1 & 0.87 \\
\hline $\begin{array}{l}\text { Bicycle } \\
\text { drawing } \\
\text { Geneva lines }\end{array}$ & 13.1 & 4.40 & 13.0 & 0.50 & 11.4 & 0.72 & 11.6 & 0.73 & 10.3 & 0.97 \\
\hline Time $L$ to $R$ & 8.4 & 4.38 & 8.4 & 0.51 & 9.6 & 0.81 & 8.7 & 0.77 & 8.7 & 1.09 \\
\hline Time $R$ to $L$ & 8.7 & 4.89 & 8.9 & 0.56 & 10.2 & 0.90 & 8.7 & 0.86 & 8.5 & 1.21 \\
\hline No. Correct R & 7.0 & 1.68 & 7.0 & 0.21 & 6.4 & 0.34 & 6.7 & 0.32 & 6.8 & 0.45 \\
\hline $\begin{array}{l}\text { No. Correct } L \\
2 \text { point } \\
\text { thresholds }\end{array}$ & 6.9 & 1.41 & 7.0 & 0.21 & 6.1 & 0.33 & 6.3 & 0.32 & 6.0 & 0.45 \\
\hline Right & 9.1 & 3.84 & 9.4 & 0.50 & 11.3 & 0.72 & 10.2 & 0.73 & 11.0 & 0.98 \\
\hline Left & 9.7 & 3.86 & 10.0 & 0.50 & 11.3 & 0.72 & 10.5 & 0.73 & 11.9 & 0.97 \\
\hline Dominant & 9.4 & 4.27 & 9.8 & 0.54 & 11.9 & 0.79 & 10.1 & 0.787 & 10.8 & 1.01 \\
\hline Non-dominant & 9.4 & 3.24 & 9.7 & 0.51 & 11.3 & 0.75 & 10.3 & 0.74 & 12.0 & 0.96 \\
\hline
\end{tabular}




\section{DISCUSSION}

Because this study used clinical cases from a tertiary treatment center, the confound between severity of psychological disorder and use of medication cannot be disentangled in a fully satisfactory manner. With this caution in mind, the comparison of strength and motor speed measures against norms based on normal participants revealed notably lower scores for both strength and speed in both genders. The sole exception was for the non-dominant hand in females, where the patient group was faster by a non-significant small amount. Various other measures showed effects to different degrees, and less conservative statistical criteria showed an even broader array of measures on which the medicated groups showed poorer performance. Other reports [54] suggest widespread cognitive effects in people experiencing their first psychotic episode regardless of whether the psychosis is due to schizophrenia, depression, or bipolar disorder.

The effects of medication are not due solely to a simple motor slowing, as few significant effects are seen on the various timed measures in the battery. Instead, there were relatively few effects, and none on the memory test. Kolb and Wishaw [27] found a fairly pervasive lowering of performance on memory tests by medicated people with schizophrenia relative to normal controls, unlike Gruzelier et al. [55], who found no difference between medicated and unmedicated cases. Tavares et al. [56] reported that people with major depressive disorder showed deficits in performance on measures of spatial memory, but those with bipolar disorder did not do so. Johnstone et al. [57] reported a correlation between memory problems and various measures of brain size in people with schizophrenia and Waters, Badcock, Dragoviä, and Jablensky [58] found no differences in performance on memory tests by those with Schneiderian first rank symptoms of schizophrenia and those without first rank symptoms. Clearly, this issue has yet to be resolved. Memory tests other than those used here may be more sensitive to medication effects.

Helmes and Fekken [59] noted that a group of patients taking both neuroleptics and antiParkinson medication scored particularly poorly on tests of finger and manual dexterity when compared to unmedicated patients. This finding was replicated by Low, Anstey, and Sachdev [60] and suggests fairly specific effects of medication on measures of fine motor control. Even so, the relatively small number of people with schizophrenia not taking medication in most populations leaves open the strong likelihood that those on medication have more disturbed behavior. The basic confound thus remains.

This study did not find any differences involving the group receiving antidepressant medication. While the correlation between diagnosed depression and receiving antidepressant medication does not approach unity, the meta-analysis by Lim et al. [15] suggests that slower performance on speeded or timed tests, such as Wechsler Digit Symbol and Trails A, is more common among people with depression than non-depressed healthy controls. There is a suggestion that the lower performance on measures of verbal learning and spatial memory [61] may be related to anti-depressant medication effects [62].

To remove patients from medication in order to conduct a medication-free neuropsychological assessment is doubtful on both ethical and practical grounds. Similarly, to ask normal volunteers to take neuroleptic medication for periods of time similar to most patients in order to conduct an experimental study of the cognitive effects of drugs is likely not ethically possible. This leaves as the only possible methods of resolving the confound to be the accumulation of sufficiently large data banks, and the selective testing of people with schizophrenia who are not taking psychoactive medication. Such studies ideally should be conducted over multiple sessions in order to minimize the influence of intra-individual variability [64]. This study also used only one or at most two measures of each major cognitive function. This accordingly limits the generalizability of the results.

For now, it seems clear that those practitioners assessing individuals taking psychotropic medication should remain aware of the strong likelihood of test performance being affected by the medication. While the majority of those with schizophrenia were taking neuroleptic medication, so were a substantial proportion of those with depression, a much more common disorder. Here, the frequent finding of poor memory in psychiatric patients in general must be tempered with the additional factor of the medication used in these cases.

\section{CONCLUSION}

This study explored the association of performance on a battery of neuropsychological 
tests that were selected for their assessment of major domains of cognitive functions. A measure of praxis for the right (dominant) hand and a measure of executive functions, perseverative responses on card sorting, were the only cognitive functions on which a group of patients taking psychoactive medication performed more poorly than a group not taking medication. Results were more limited than predicted and showed that the use of neuroleptic drugs alone or antidepressants is not associated with impaired performance on the test battery used.

\section{AUTHOR'S NOTES}

Aspects of these data were presented at the annual meeting of the Canadian Psychological Association, Halifax, Nova Scotia, 1989; at the $4^{\text {th }}$ International Conference on Memory, Sydney, 2006; and the $31^{\text {st }}$ conference of the Australian Society for the Study of Brain Impairment, Melbourne, 2008.

\section{CONSENT}

It is not applicable.

\section{ETHICAL APPROVAL}

It is not applicable.

\section{COMPETING INTERESTS}

Author has declared that no competing interests exist.

\section{REFERENCES}

1. Lezak MD, Howieson DB, Bigler ED, Tranel D. Neuropsychological assessment. $\left(5^{\text {th }} \mathrm{ed}\right.$.) New York. Oxford University Press; 2012.

2. American psychiatric association diagnostic and statistical manual of mental disorders. Text revision. ( $5^{\text {th }}$ ed.) Washington, DC: American Psychiatric Association; 2013.

3. Barlow DH, Bullis JR, Comer JS, Ametaj AA. Evidence-based psychological treatments: An update and a way forward. Annual Review of Clinical Psychology. 2013; 9:1-27.

4. Seaton BE, Goldstein G, Allen DN. Sources of heterogeneity in schizophrenia: The role of neuropsychological functioning. Neuropsychology Review. 2001;11:45-67.

5. Tervo K. Neurocognitive consequences of substance use in schizophrenia: Are there additive effects? In Kalechstein A, W. G. Van Gorp (Eds.). Neuropsychology and substance use: State-of-the-art and Future Directions. New York: Taylor and Francis. 2007;349-376.

6. Blanchard JJ, Neale JM. Medication status of participants in psychopathology research: Selective review of current reporting practices. Journal of Abnormal Psychology. 1992;101:731-734.

7. Adams KM, Rennick PM, Schoof KG, Keegan JF. Neuropsychological measurement of drug effects: Polydrug research. Journal of Psychedelic Drugs. 1975;7:151-160.

8. Morris JA, Lawson WM. Neuropsychological deficits in patients with alcohol and other psychoactive substance abuse and dependence: A pilot study. Alcoholism Treatment Quarterly. 1998;16:101-111.

9. Paraherakis A, Charney DA, Gill K. Neuropsychological functioning in substance-dependent patients. Substance Use \& Misuse. 2001;36:257-271.

10. Irani F, Kalkstein S, Moberg EA, Moberg PJ. Neuropsychological performance in older patients with schizophrenia: A metaanalysis of cross-sectional and longitudinal studies. Schizophrenia Bulletin. 2011;37: 1318-1326.

11. Yozawitz A. Applied neuropsychology in a psychiatric center. In Grant I, Adams KM. (Eds.). Neuropsychological assessment of neuropsychiatric disorders. New York: Oxford University Press. 1986;121-146

12. Bornstein RA, Nasrallah HA, Olson SC, Coffman J, Schwartzkopf S, Torello M. Neuropsychological deficit in subtypes of schizophrenia: Comparison of paranoid, non-paranoid, and schizoaffective groups. Presented at the annual meeting of the American Psychological Association; 1988.

13. Perlick D, Stastny P, Katz I, Mayer M, Mattis $S$. Memory deficits and anticholinergic levels in chronic schizophrenia. American Journal of Psychiatry. 1986;143:230-232.

14. Fokas K, Bozikas V. Longitudinal course of cognitive deficits in schizophrenia. Psychiatriki. 2009;20:119-120.

15. Lim J, Oh IK, Han C, Huh YJ, Jung IK, Patkar AA, et al. Sensitivity of cognitive tests in four cognitive domains in discriminating MDD patients from healthy controls: A metaanalysis. International Psychogeriatrics. 2013;25:1543-1557.

16. Heaton RK, Baade LE, Johnson KL. Neuropsychological test results associated 
with psychiatric disorders in adults. Psychological Bulletin. 1978;85:141-162.

17. Heaton RK, Crowley TJ. Effects of psychiatric disorders and their somatic treatments on neuropsychological test results. In. Filskov SB, Boll TJ. (Eds.) Handbook of clinical neuropsychology. New York: Wiley. 1981;481-525.

18. Heinrichs RW. The primacy of cognition in schizophrenia. American Psychologist. 2005;60:229-242.

19. Heinrichs RW, Zakzanis KK. Neurocognitive deficit in schizophrenia: A quantitative review of the evidence. Neuropsychology. 1998;12:426-445.

20. Malec J. Neuropsychological assessment of schizophrenia versus brain damage: A review. Journal of Nervous and Mental Disease. 1978;166:507-516.

21. Raz S, Raz N. Structural brain abnormalities in the major psychoses: A quantitative review of the evidence from computerized imaging. Psychological Bulletin. 1990;108: 93-108.

22. Weinberger DR, Wagner RL, Wyatt RJ. Neuropathological studies of schizophrenia: A selective review. Schizophrenia Bulletin. 1983;9:193-212.

23. Spohn HE, Lacoursiere RB, Thompson K, Coyne L. Phenothiazine effects on psychological and psychophysiological dysfunction in chronic schizophrenics. Archives of General Psychiatry. 1977;34: 633-644.

24. Strauss ME, Lew MF, Coyle JT, Tune LE. Psychopharmacologic and clinical correlates of attention in chronic schizophrenia. American Journal of Psychiatry. 1985;142: 497-499.

25. Braff DL, Saccuzzo DP. Effect of antipsychotic medication on speed of information processing in schizophrenic patients. American Journal of Psychiatry. 1982;139:1127-1130.

26. Tune LE, Strauss ME, Lew MF, Breitlinger E, Coyle JT. Serum levels of anticholinergic drugs and impaired recent memory in chronic schizophrenic patients. American Journal of Psychiatry. 1982;139:1460-1462.

27. Kolb B, Wishaw IQ. Performance of schizophrenic patients on tests sensitive to left or right frontal, temporal, or parietal function in neurological patients. Journal of Nervous and Mental Disease. 1983;171: 435-443.

28. Erwin BJ, Rosenbaum G. Parietal lobe syndrome and schizophrenia: Comparison of neuropsychological deficits. Journal of Abnormal Psychology. 1979;88:234-241.

29. Howard ML, Hogan TP, Wright MW. The effects of drugs on psychiatric patients performance on the Halstead-Reitan neuropsychological test battery. Journal of Nervous and Mental Disease. 1975;161: 166-171.

30. Gruzelier JH, Hammond NV. The effect of chlorpromazine upon psychophysiological, endocrine and information processing measures in schizophrenia. Journal of Psychiatric Research. 1978;14:167-182.

31. Schretlen DJ, Testa SM, Winicki JM, Pearlson GD, Gordon B. The frequency and bases of abnormal performance by healthy adults on neuropsychological testing. Journal of the International Neuropsychological Society. 2008;14:436-445.

32. Kolb B, Wishaw IQ. Fundamentals of human neuropsychology. ( $2^{\text {nd }}$ ed.). San Francisco: W.H. Freeman; 1985.

33. Kolb B, Wishaw IQ. Fundamentals of human neuropsychology. ( $3^{\text {rd }}$ ed.). San Francisco: W. H. Freeman; 2008.

34. World Health Organization. International classification of diseases: Manual of the international statistical classification of diseases, injuries, and causes of death. Ninth revision. Congress, 1975. Geneva: Author; 1977.

35. Halstead WC. Brain and intelligence: A quantitative study of the frontal lobes. Chicago: University of Chicago Press; 1947.

36. Arthur G. A point scale of performance tests. Clinical manual. Chicago: Stoelting. 1943;1.

37. Flynn JR. Searching for justice: The discovery of IQ gains over time. American Psychologist. 1999;54:5-20.

38. Wechsler D. WAIS-IV technical and interpretive manual. San Antonio, TX: Pearson; 2008.

39. Wechsler D. WMS-IV technical and interpretive manual. San Antonio. TX: Pearson; 2009.

40. Kimura D. Right temporal-lobe damage: Perception of unfamiliar stimuli after damage. Archives of Neurology. 1963;8: 264-271.

41. De Renzi E, Faglioni P. Normative data and screening power of a shortened version of the Token Test. Cortex. 1978;14:41-49.

42. Kimura D. Manual activity during speaking. II. Left-handers. Neuropsychologia. 1973; 11:51-55.

43. Flowers KA, Hudson JM. Motor laterality as an indicator of speech laterality. 
Neuropsychology. 2013;27:256-265.

44. Dodrill CB. The hand dynamometer as a neuropsychological measure. Journal of Consulting and Clinical Psychology. 1978;46:1432-1435.

45. Kimura D. Acquisition of a motor skill after left-hemisphere damage. Brain. 1977;100: 527-542.

46. Corkin S, Milner B, Rasmussen T. Somatosensory thresholds: Contrasting effects of postcentral- gyrus and posterior parietal-lobe excisions. Archives of Neurology. 1970;23:41-58.

47. Kimura D, Barnett HJM, Burkhart G. The psychological test pattern in progressive supranuclear palsy. Neuropsychologia. 1981;19:301-306.

48. Lezak MD. Neuropsychological assessment. $\left(2^{\text {nd }}\right.$ ed.) New York: Oxford University Press; 1983.

49. Kimura D, Archibald $Y$. Motor functions of the left hemisphere. Brain. 1974;97:337-350.

50. Nelson HE. A modified card sorting test sensitive to frontal lobe defects. Cortex. 1976;12:313-324.

51. Heaton RK, Chelune GJ, Talley JL, Kay G. C, Curtiss G. Wisconsin card sorting test manual (revised and expanded). Odessa, FL: Psychological Assessment Resources; 1993.

52. Kimura D. Neuropsychology test procedures. London. Ont.: DK Consultants; 1984.

53. Mitrushina M, Boone KB, Razani J, D'Elia, L. F. Handbook of normative data for neuropsychological assessment. (2 ${ }^{\text {nd }}$ ed.) Oxford: Oxford University Press; 2005.

54. Wilkinson L. Systat: The system for statistics. Evanston, IL: Systat. Inc; 1990.

55. Gruzelier J, Seymour K, Wilson L, Jolley A. Hirsch S. (Impairments on neuropsychologic tests of temporohippocampal and frontohippocampal functions and word fluency in remitting schizophrenia and affective disorders. Archives of General Psychiatry. 1988;45:623-629.

56. Tavares JVT, Clark L, Cannon DM, Erickson K, Drevets WC, Sahakian BJ. Distinct profiles of neurocognitive function in unmedicated unipolar depression and bipolar II depression. Biological Psychiatry. 2007;62:917-924.

57. Johnstone EC, Owens DGC, Bydder GM, Colter N, Crow TJ, Frith CD. The spectrum of structural brain changes in schizophrenia: Age of onset as a predictor of cognitive and clinical impairments and their cerebral correlates. Psychological Medicine. 1989;19: 91-103.

58. Waters FAV, Badcock JC, Dragoviä M, Jablensky A. Neuropsychological functioning in schizophrenia patients with first-rank (passivity) symptoms. Psychopathology. 2009;42:47-58.

59. Helmes E, Fekken GC. Effects of psychotropic drugs and psychiatric illness on vocational aptitude and interest assessment. Journal of Clinical Psychology. 1986;42: 569-576.

60. Low LF, Anstey KJ, Sachdev P. Use of medications with anticholinergic properties and cognitive function in a young-old community sample. International Journal of Geriatric Psychiatry. 2009;24:578-584.

61. Bourke C, Porter RJ, Carter JD, McIntosh VV, Jordan J, Bell C, et al. Comparison of neuropsychological functioning and emotional processing in major depression and social anxiety disorder subjects, and matched healthy controls. Australian and New Zealand Journal of Psychiatry. 2012;46:972-981.

62. Culang ME, Sneed JR, Keilp JG, Rutherford BR, Pelton GH, Devanand DP, et al. Change in cognitive functioning following acute antidepressant treatment in late-life depression. The American Journal of Geriatric Psychiatry. 2009;17:881-888.

63. Rey A. L'examen clinique en psychologie. Paris: Presse universitaires de France; 1970.

64. Salthouse TA. Implications of within-person variability in cognitive and neuropsychological functioning for the interpretation of change. Neuropsychology. 2007;21:401-411.

(C) 2016 Helmes; This is an Open Access article distributed under the terms of the Creative Commons Attribution License (http://creativecommons.org/licenses/by/4.0), which permits unrestricted use, distribution, and reproduction in any medium, provided the original work is properly cited.

Peer-review history:

The peer review history for this paper can be accessed here: http://sciencedomain.org/review-history/11586 